\title{
Role of Membrane Lipid Peroxidation, Enzymatic and Non-enzymatic Antioxidative Systems in the Development of Chilling Injury in Japanese Plums
}

\author{
Sukhvinder Pal Singh ${ }^{1}$ and Zora Singh ${ }^{2}$ \\ Curtin Horticulture Research Laboratory, Department of Environment and Agriculture, School of \\ Science, Faculty of Science and Engineering, and International Institute of Agri-Food Security \\ (IIAFS), Curtin University, GPO Box U1987, Perth, Western Australia 6845, Australia
}

\begin{abstract}
Additional INDEX words. ascorbate-glutathione cycle, cold storage, enzymatic antioxidants, ethylene, non-enzymatic antioxidants, oxidative stress, phenolics, respiration

Abstract. Chilling injury (CI) is a major postharvest constraint in the long-term cold storage, transportation, and distribution of japanese plums (Prunus salicina). The aim of the work was to explain the development and severity of CI in japanese plums based on the oxidative stress theory following time course analysis of enzymatic and nonenzymatic antioxidants. Changes in membrane lipid peroxidation and enzymatic and non-enzymatic antioxidative systems in japanese plum cultivar Blackamber were determined at weekly intervals during 5 weeks of cold storage at $0^{\circ} \mathrm{C}$ and at 2-day intervals during poststorage simulated shelf conditions $\left(21 \pm 1^{\circ} \mathrm{C}\right)$ for 8 days after each week of cold storage. Fruit respiration and ethylene production rates showed typical climacteric patterns after removal from cold storage and these rates were relatively high after 4 and 5 weeks compared with 0 to 3 weeks of storage. The CI symptoms first appeared after 3 weeks of cold storage after fruit had been transferred to simulated shelf conditions. The incidence and severity of CI intensified with increasing storage duration. The extent of lipid peroxidation indicated by concentration of thiobarbituric acid-reactive substances and membrane damage manifested as electrolyte leakage increased with increasing duration of storage and subsequent simulated shelf conditions. Membrane lipid peroxidation exhibited positive correlation with the severity of CI. Activities of primary antioxidant enzymes and the enzymes involved in the ascorbate-glutathione cycle were determined to explain the levels of reduced and oxidized forms of cellular redox buffers, ascorbate and glutathione. In response to chilling stress, antioxidative protection systems operated efficiently during the first 3 weeks of cold storage, but extended storage resulted in loss of ability to ameliorate increasing levels of oxidative stress. In this study, the comprehensive analyses of various metabolites and antioxidative systems explain the series of events involved in development of CI in japanese plums in support of the oxidative stress theory.
\end{abstract}

Postharvest oxidative stress is a phenomenon caused by an imbalance in the production and scavenging of reactive oxygen species (ROS) in the fruit during postharvest handling and storage (Hodges et al., 2004). ROS such as superoxide anion $\left(\mathrm{O}_{2}^{-}\right)$, hydrogen peroxide $\left(\mathrm{H}_{2} \mathrm{O}_{2}\right)$, nitric oxide $\left(\mathrm{NO}^{-}\right)$, and peroxynitrite $\left(\mathrm{ONOO}^{\circ}\right)$ are produced in plants under normal and stress conditions (Apel and Hirt, 2004). If these are not removed or detoxified by the enzymatic and non-enzymatic antioxidants, they accumulate to toxic levels in the cell and can also serve as the precursors for the generation of more toxic ROS such as hydroxyl radicals $\left(\mathrm{OH}^{*}\right)$. The presence of ROS at higher levels and reduction in the capability of the antioxidant protection system can lead to oxidative damage in the tissue (Hodges et al., 2004). The study of dynamics of antioxidants

Received for publication 21 June 2012. Accepted for publication 7 Aug. 2012. We are grateful to W.B. McGlasson (University of Western Sydney) and P.M.A. Toivonen (Agriculture and Agri-Food Canada) for critically reviewing the manuscript. S.P. Singh acknowledges the Department of Education, Employment and Work Relations (DEEWR), the Commonwealth of Australia, and Curtin University for financial support during his $\mathrm{PhD}$ degree. Special thanks to D.M. Hodges (Agriculture and Agri-Food Canada) for sharing laboratory protocols. We thank Susan Petersen for technical support and Casuarina Valley Orchards for providing experimental fruit material.

${ }^{1}$ Current address: National Agri-Food Biotechnology Institute (NABI), Mohali, Punjab 160071 India.

${ }^{2}$ Corresponding author. E-mail: z.singh@curtin.edu.au. in the fruit is important for mainly three reasons. First, the presence of higher levels of antioxidants protects the fruit from potentially toxic ROS thereby providing stress tolerance (Davey et al., 2004). Second, the nutritional value of fruit attributable to the antioxidants is important from a human consumption perspective (Gil et al., 2002). Third, it has been widely argued that the higher concentrations of antioxidants in the peel and flesh tissues of fruit reduced the incidence of senescence-related disorders (Hodges et al., 2004).

Fruit of japanese plum are chilling-sensitive (Crisosto et al., 2004; Singh et al., 2009). The sensitivity to chilling depends on several factors including genotype, harvest maturity, storage temperature, and storage period and shelf life (Crisosto et al., 1999; Singh et al., 2009). CI symptoms in japanese plums include flesh browning, translucency, mealiness, and bleeding or bladderiness. CI has been proposed to be an oxidative phenomenon linked to the production of ROS causing lipid peroxidation, membrane damage, and overall reduced capacity of antioxidant systems (Hodges et al., 2004; Singh and Singh, 2012). Under normal and mild stress conditions, ROS have been known to act as signaling molecules in a variety of metabolic processes such as enhancement of antioxidant protection systems and gene regulation to affect metabolic responses to ameliorate the stress response (Toivonen, 2004). On the other hand, in response to the prolonged or severe stress conditions, the ROS production may exceed the 
capacity of the system to scavenge them, and subcellular and cellular damage can occur.

Toivonen (2004) emphasized the importance of the dynamic nature of the oxidative processes in plant systems and suggested that time course analysis with multiple time samplings could improve understanding of the role of enzymatic and nonenzymatic antioxidants in response to postharvest stress conditions. Currently, such comprehensive information on the dynamics of antioxidants during chilling stress in many fruit including japanese plums is not available. Therefore, the objective was to understand the development and severity of CI in japanese plums based on the oxidative stress theory following time course analysis of enzymatic and non-enzymatic antioxidants in a multiple sampling framework.

\section{Materials and Methods}

Fruit MATERial AND COLD STORAGE. Japanese plum cultivar Blackamber fruit were manually harvested at commercial maturity (soluble solids concentration $=10.9 \% \pm 0.1 \%$, titratable acidity $=1.4 \% \pm 0.1 \%$, and firmness $=53.4 \pm 2.1 \mathrm{~N}$ ) in the early morning hours from the Casuarina Valley Orchards, Karragullen, Perth Hills, Western Australia (lat. 31 $57^{\prime}$ S, long. $115^{\circ} 50^{\prime}$ E). Fruit were transported to the laboratory within $2 \mathrm{~h}$ after harvest and blemished and diseased fruit were discarded. Fruit were placed in plastic crates lined with $30-\mu \mathrm{m}$-thick low-density polyethylene film folded over them and stored at $0{ }^{\circ} \mathrm{C}$ for 5 weeks. Control fruit (100 fruit per replicate, $n=3$ ) were held at $21 \pm 1{ }^{\circ} \mathrm{C}$ to simulate shelf conditions for $8 \mathrm{~d}$ without cold storage and 20 fruit per replicate were analyzed at 2-d intervals $(0,2,4,6$, and $8 \mathrm{~d}$ ) for various parameters. Aliquots of 100 fruit from each replication $(n=3)$ were removed from cold storage at weekly intervals and held for $8 \mathrm{~d}$ to simulate shelf conditions $\left(21 \pm 1^{\circ} \mathrm{C}\right)$. Twenty fruit as a single replicate were analyzed at 2-d intervals $(0,2,4,6$, and $8 d)$. The fruit was peeled and the flesh tissue was cut into small cubes and immediately frozen with liquid nitrogen and stored at $-80{ }^{\circ} \mathrm{C}$ for further analyses. The experiment used a completely randomized design with two factors including cold storage and simulated shelf conditions.

RESPIRATION AND ETHYLENE PRODUCTION RATES. Two fruit per replicate were enclosed in an airtight container $(1 \mathrm{~L})$ fitted with a rubber septum for $1 \mathrm{~h}$ at room temperature $\left(21 \pm 1^{\circ} \mathrm{C}\right)$. The rates of respiration and ethylene production were measured daily by analyzing headspace composition (Singh et al., 2009) during $8 \mathrm{~d}$ at simulated shelf conditions after each week of storage, starting from Week 0 . The respiration and ethylene production rates were expressed as millimoles $\mathrm{CO}_{2}$ evolved per kilogram per hour and micromoles ethylene per kilogram per hour, respectively.

Chilling InJury. The incidence and severity of CI were evaluated $4 \mathrm{~h}$ after removal from cold storage and at 2 -d intervals during simulated shelf conditions for $8 \mathrm{~d}$. Twenty fruit per replication were cut around the equatorial axis, the two halves of each fruit were separated by twisting in opposite directions, and the mesocarp was examined for symptoms such as flesh browning, mealiness, and translucency. The incidence and severity of CI were assessed as described by Singh et al. (2009). Briefly, CI severity was determined using a 5-point hedonic scale based on the surface area of fruit flesh affected. The scale used was: $0=$ $0 \%$ area affected, $1=1 \%$ to $20 \%$ area affected, $2=21 \%$ to $40 \%$ area affected, $3=41 \%$ to $60 \%$ area affected, $4=61 \%$ to $80 \%$ area affected, and $5=$ greater than $80 \%$ area affected. The CI index was calculated by multiplying the number of fruit scored with the same value of the hedonic scale with the corresponding scale number. Finally, the resultant number was divided by the total number of fruit. CI incidence was expressed as the percentage of affected fruit irrespective of the severity level.

THIOBARBITURIC ACID-REACTIVE SUBSTANCES, LIPOXYGENASE ACTIVITY, AND ELECTROLYTE LEAKAGE. Thiobarbituric acidreactive substance (TBARS) concentration was determined as previously described (Singh et al., 2012) and was expressed as nanomoles malondialdehyde equivalents per gram of fresh weight (FW). The activity of lipoxygenase (LOX) was determined by measuring the increase in absorbance at $234 \mathrm{~nm}$ as a result of formation of a diene conjugate from linoleic acid (Singh et al., 2012). LOX activity was expressed as micromoles linoleic hydroperoxide formed per minute per milligram of protein. Electrolyte leakage (EL) as a measure of membrane integrity was determined as described in Singh et al. (2012). The data were expressed as percentage of the total EL.

EXTRACTION AND ASSAYS OF ANTIOXIDANT ENZYMES. Enzyme extracts of superoxide dismutase (SOD), catalase (CAT), and peroxidase (POD) were prepared and assays were performed as previously described (Singh et al., 2012). SOD assay involved the measurement of cytochrome $\mathrm{c}(\mathrm{Cyt} \mathrm{c})$ reduction by superoxide anions generated in the xanthine-xanthine oxidase system and of the inhibition of Cyt $\mathrm{c}$ reduction by SOD. SOD activity was expressed as micromoles Cyt c conserved per minute per milligram protein. CAT activity was assayed by measuring a decrease in the absorbance at $240 \mathrm{~nm}$ for $3 \mathrm{~min}$ as a result of decomposition of $\mathrm{H}_{2} \mathrm{O}_{2}$. CAT activity was expressed as micromoles $\mathrm{H}_{2} \mathrm{O}_{2}$ decomposed per minute per milligram protein. For determination of POD activity, the increase in absorbance at $470 \mathrm{~nm}$ was monitored for $3 \mathrm{~min}$ with and without addition of enzyme extract. POD activity was expressed as micromoles $\mathrm{H}_{2} \mathrm{O}_{2}$ decomposed per minute per milligram protein.

DETERMINATION OF REDUCED ASCORBATE, DEHYDROASCORBATE, AND TOTAL ASCORBATE. The extraction procedure for ascorbate (AA) and dehydroascorbate (DHA) was followed as described by Davey et al. (2004) with some modifications (Singh et al., 2012). High-performance liquid chromatography (HPLC) was performed for determination of AA, DHA, and AA + DHA (Singh et al., 2012). Total ascorbate concentration was determined by the reduction of DHA into AA using dithiothreitol as a reducing agent. The reduced samples were then directly analyzed for total ascorbate by HPLC under similar conditions as for AA. For each sample, the concentration of DHA was obtained by subtracting AA from the total ascorbate (AA + DHA) (Davey et al., 2004). The concentrations of AA, DHA, and AA + DHA were expressed as nanomoles per gram FW.

Determination OF REDUCED GLUTATHIONE, OXIDIZED GLUTATHIONE, AND TOTAL GLUTATHIONE. Glutathione [total and oxidized glutathione (GSSG)] was assayed spectrophotometrically by the 5,5'-dithiobis-(2-nitrobenzoic acid)-glutathione reductase (GR) recycling method (Hodges and Forney, 2000). The extraction and assay procedures for glutathione (GSH) and GSSG have been described elsewhere (Singh et al., 2012). The concentrations of glutathione (GSH, GSSG, and GSH + GSSG) were expressed as nanomoles per gram FW.

EXTRACTION AND ASSAYS OF ASCORBATE-GLUTATHIONE CYCLE ENZYMES. The extracts of enzymes involved in the ascorbateglutathione cycle were prepared and assays were performed as previously described (Singh et al., 2012). The activities of ascorbate peroxidase (APX), monodehydroascorbate reductase (MDHAR), dehydroascorbate reductase (DHAR), GR, 
and glutathione-S-transferase (GT) were measured and were expressed as micromoles ascorbic acid oxidized per minute per milligram protein, micromoles NADH oxidized per minute per milligram protein, micromoles DHA oxidized per minute per milligram protein, nanomoles NADPH oxidized per minute per milligram protein, and nanomoles S-2,4-dinitrophenylglutathione formed per minute per milligram protein, respectively.

DETERMINATION OF TOTAL PHENOLICS AND ANTIOXIDANT ACTIVITY. Total phenolic compounds were quantified by following the Folin-Ciocalteu reagent -based colorimetric method (Singleton et al., 1999). Gallic acid equivalent (GAE), most commonly used to express the total phenolics in fruit, was not followed because 3-o-caffeoylquinic acid (neochlorogenic acid) was the major hydroxycinnamate in japanese plum and european plum (Prunus domestica) flesh tissue (Tomás-Barberán et al., 2001). The total phenolics concentration in chlorogenic- or neochlorogenic-rich fruit is underestimated by 0.6 times if expressed in terms of GAE. Similar absorption spectra of chlorogenic and neochlorogenic acids allow the use of former in the preparation of calibration curve (Chun and Kim, 2004). The concentration of total phenolics was expressed in terms of milligrams chlorogenic acid equivalents per $100 \mathrm{~g} \mathrm{FW}$. The antioxidant activity was determined using the method of Brand-Williams et al. (1995) and expressed in terms of milligrams ascorbic acid equivalents per $100 \mathrm{~g} \mathrm{FW}$.

STatistical analysis. The data were subjected to two-way analysis of variance (ANOVA) using GenStat (Release 11.1;

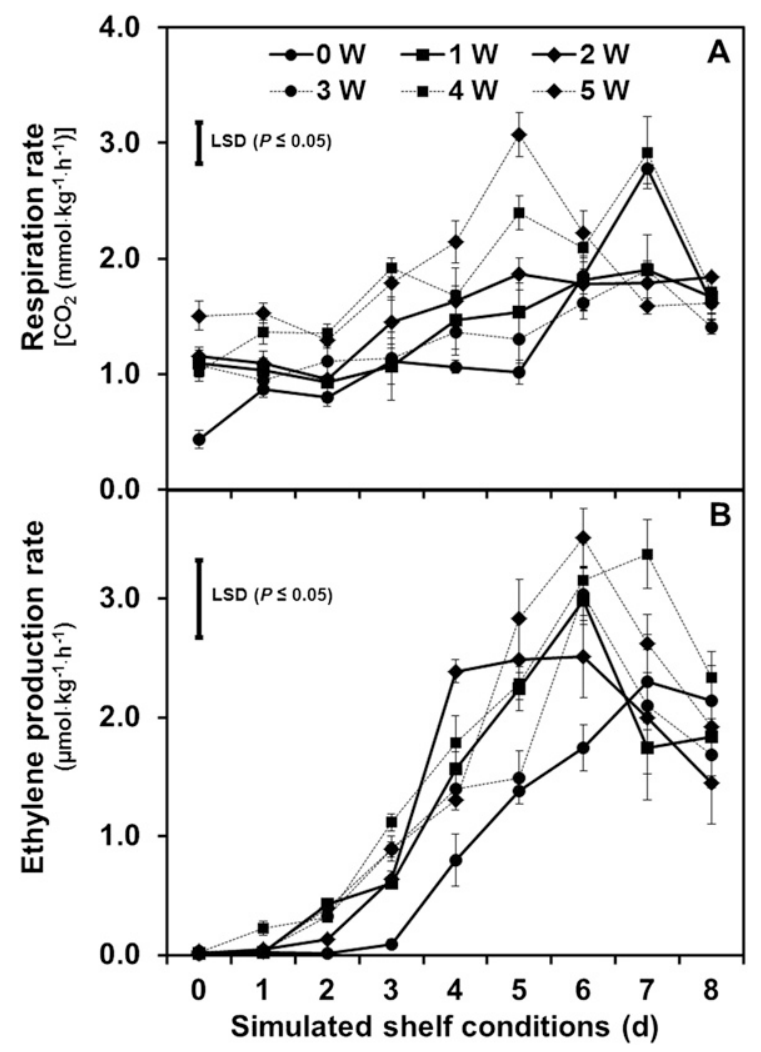

Fig. 1. The rates of respiration (A) and ethylene production (B) in 'Blackamber' japanese plums as influenced by cold storage at $0{ }^{\circ} \mathrm{C}$ for 0 to 5 weeks (W) plus $8 \mathrm{~d}$ of simulated shelf conditions $\left(21 \pm 1^{\circ} \mathrm{C}\right)$. Measurements were made on daily basis for $8 \mathrm{~d}$ after each week of cold storage (two fruit/experimental unit). Error bars represent SE. Least significant differences $(P \leq 0.05)$ for interaction between cold storage and simulated shelf conditions are shown as bars.
VSN Intl., Hemel Hempstead, U.K.). Before statistical analysis, the data on CI incidence were subjected to arsine transformation to reduce heteroscedasticity. The effects of cold storage, simulated shelf holding, and their interactions on different parameters were assessed within ANOVA and the least significant differences were calculated following a significant Fisher's test at $P \leq 0.05$. All the assumptions of analysis were checked to ensure validity of statistical analysis.

\section{Results and Discussion}

RESPIRATION AND ETHYLENE PRODUCTION. 'Blackamber' is a climacteric-type japanese plum cultivar (Singh et al., 2012) and its storage potential is, therefore, influenced by physiological processes such as rates of respiration and ethylene production. Higher rates of respiration and ethylene production in 'Blackamber' japanese plums were observed after removal from cold storage compared with control and the onset of climacteric was also brought forward by prolonged storage (Fig. 1A-B). The climacteric patterns observed during fruit ripening indicated that prolonged cold storage did not affect normal fruit ripening in japanese plums but accelerated and enhanced physiological processes. Candan et al. (2008) reported that cold storage increased ethylene production in

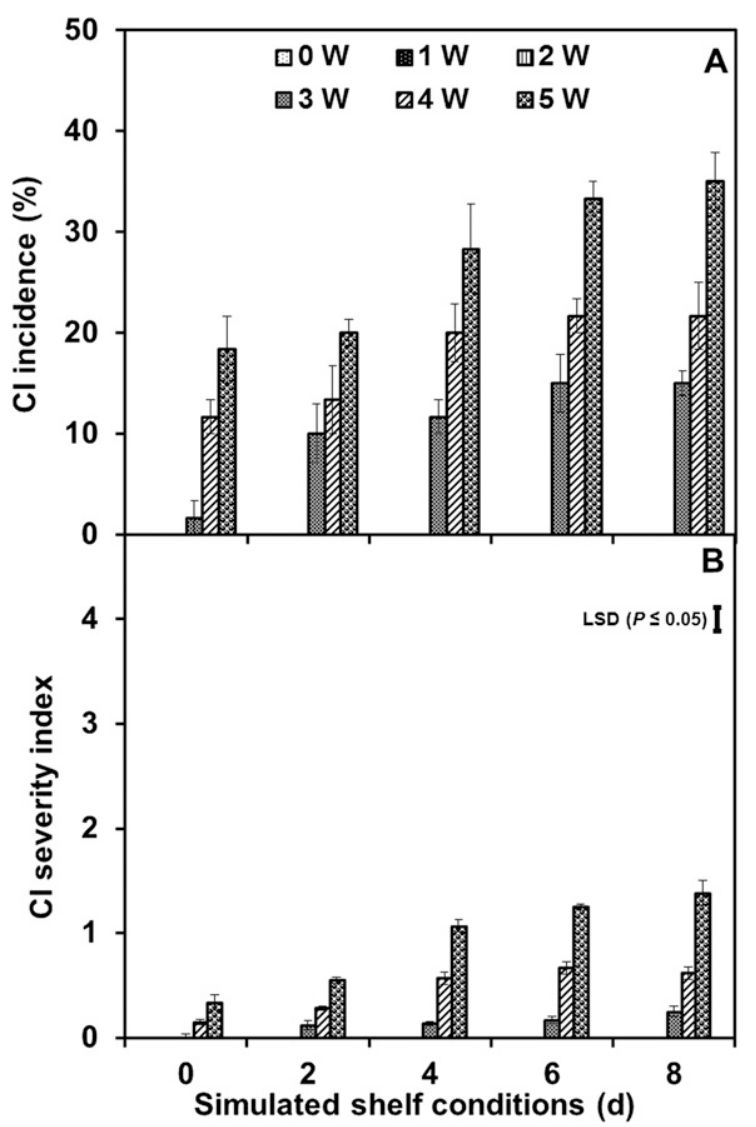

Fig. 2. Chilling injury (CI) incidence (A) and CI severity index (B) in 'Blackamber' japanese plums as influenced by cold storage at $0{ }^{\circ} \mathrm{C}$ for 0 to 5 weeks (W) plus $8 \mathrm{~d}$ of simulated shelf conditions $\left(21 \pm 1^{\circ} \mathrm{C}\right)$. Observations were recorded ( 20 fruit/replicate) on 2-d intervals during simulated shelf conditions after each week of cold storage. Error bars represent SE. Data on CI incidence were arsine-transformed, but back-transformed data are presented. Least significant differences $(P \leq 0.05)$ for interaction between cold storage and simulated shelf conditions are shown as bars. 
'Larry Ann' japanese plums, but the number of days to reach the ethylene peak was independent of the storage period. Cold storage of 'Tegan Blue' japanese plums at $0{ }^{\circ} \mathrm{C}$ has been reported to promote the accumulation of 1-aminocyclopropane1-carboxylic acid (ACC) during storage for 3 and 6 weeks and increase the activities of ACC synthase and ACC oxidase (Khan and Singh, 2009). This could explain the rise in ethylene production in our experiment triggered by the exposure to simulated shelf conditions after 4 and 5 weeks of cold storage.

Chilling InJury. The CI symptoms in the form of flesh browning and mealiness appeared at ambient conditions after transfer from 3 weeks of cold storage, but the incidence and

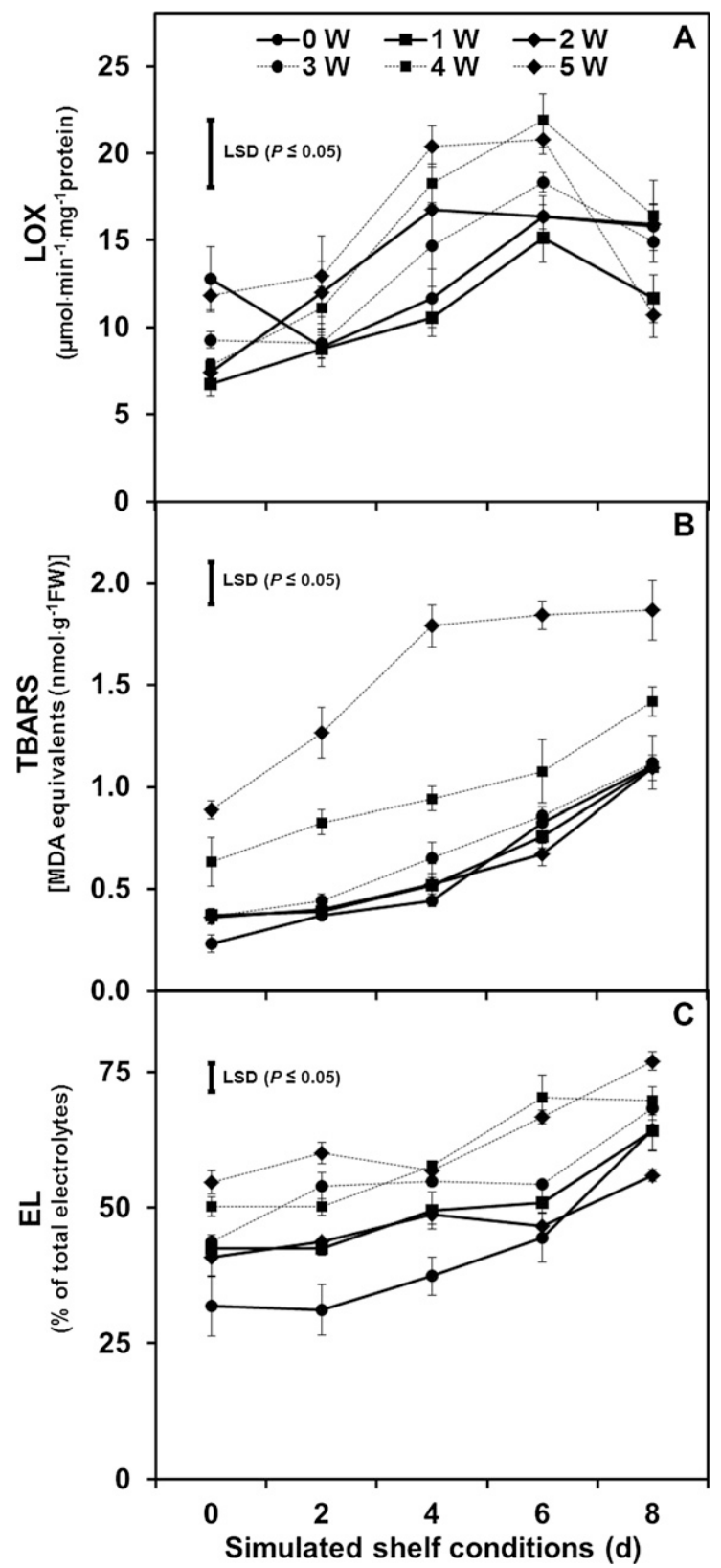

Fig. 3. Changes in lipoxygenase (LOX) activity (A), thiobarbituric acid-reactive substances (TBARS) concentration (B), and electrolyte leakage (EL; C) in the flesh tissue of 'Blackamber' japanese plums as influenced by cold storage at $0{ }^{\circ} \mathrm{C}$ for 0 to 5 weeks (W) plus $8 \mathrm{~d}$ of simulated shelf conditions $\left(21 \pm 1{ }^{\circ} \mathrm{C}\right)$. Error bars represent SE. Least significant differences $(P \leq 0.05)$ for interaction between cold storage and simulated shelf conditions are shown as bars. severity of CI were very low (Fig. 2). With the advancement of storage period at both cold and simulated shelf conditions, the incidence and severity of CI increased; the CI index was very low (less than 1) after 4 weeks and low (less than 2) after 5 weeks of cold storage. Flesh bleeding was also observed as the fruit ripening progressed after 5 weeks of cold storage. Crisosto et al. (2004) reported that 'Blackamber' can be stored at $0{ }^{\circ} \mathrm{C}$ for 5 weeks and its market life is limited beyond this period as a result of CI symptoms expressed as flesh browning, mealiness, and translucency. The loss of $25 \%$ or greater fruit as a result of $\mathrm{CI}$ has been considered to be a benchmark to determine the storage potential in japanese plums (Crisosto et al., 2004) and therefore the end of storage life of 'Blackamber' japanese plums was 4 weeks at $0{ }^{\circ} \mathrm{C}$ in our experiment.

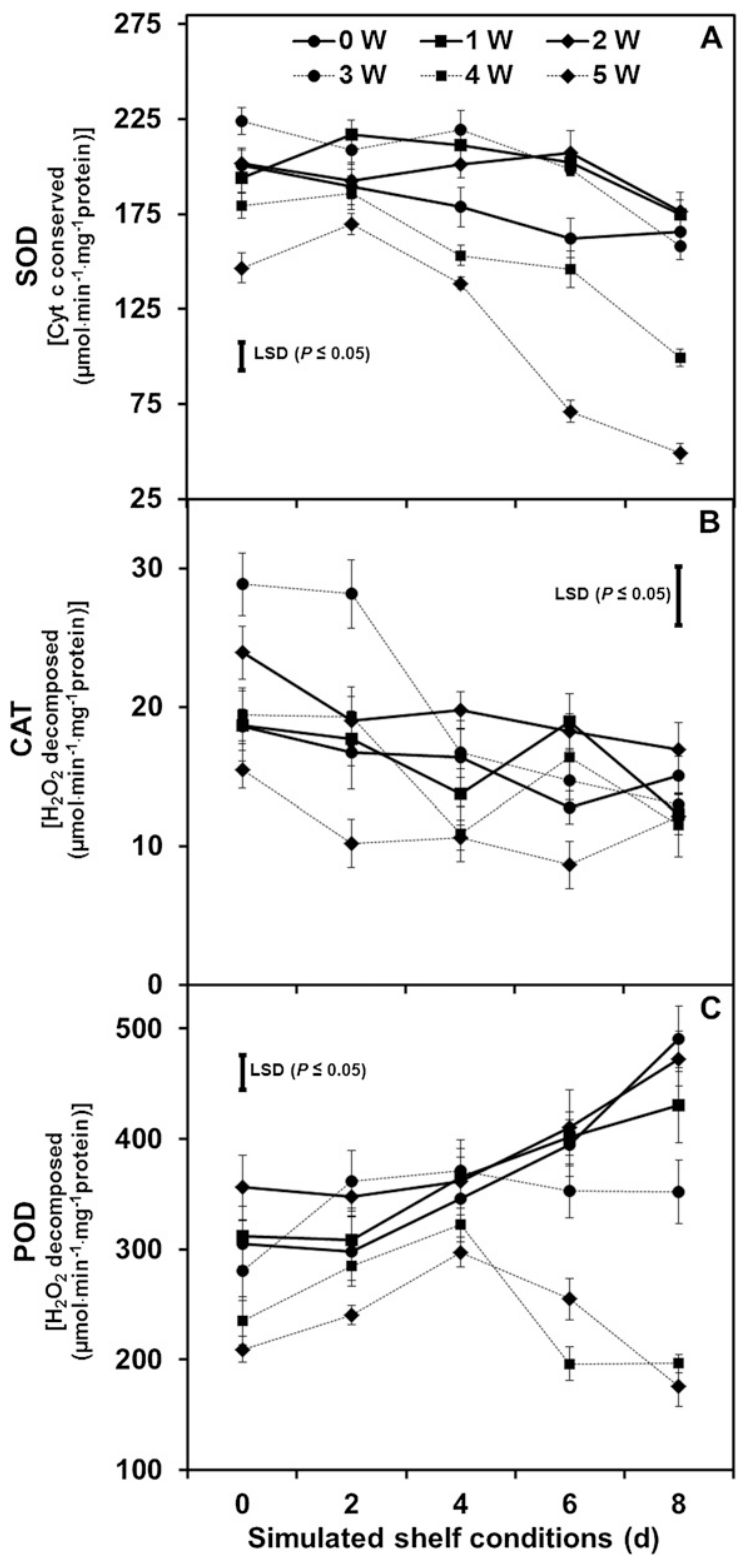

Fig. 4. Changes in activities of (A) superoxide dismutase (SOD), (B) catalase (CAT), and (C) peroxidase (POD) in the flesh tissue of 'Blackamber' japanese plums as influenced by cold storage at $0{ }^{\circ} \mathrm{C}$ for 0 to 5 weeks (W) plus $8 \mathrm{~d}$ of simulated shelf conditions $\left(21 \pm 1^{\circ} \mathrm{C}\right)$. Error bars represent SE. Least significant differences $(P \leq 0.05)$ for interaction between cold storage and simulated shelf conditions are shown as bars. 
LIPID PEROXIDATION. The LOX activity increased during fruit ripening after removal from cold storage (Fig. 3A). The LOX is a multifunctional key enzyme involved in the biosynthesis of aroma-volatile compounds during fruit ripening and also in defense-related pathways (Shewfelt and Purvis, 1995). The increase in the concentration of TBARS in fruit flesh during cold storage and simulated shelf conditions was an indication of the peroxidative damage caused to the fruit tissue; the extent of damage increased significantly at 4 and 5 weeks of cold storage (Fig. 3B). The higher concentration of TBARS toward the later stages of storage indicated higher levels of oxidative stress, which might have developed as a result of increased concentration of the ROS and/or decreased capability of the antioxidant protection system. The peroxidation of free polyunsaturated fatty acids by LOX causes accumulation of lipid hydroperoxides, which can further decompose to yield oxyradicals, ethane, and TBARS. The concentration of TBARS was found to be positively correlated $(r=0.83)$ with the severity of CI. It has been previously reported that TBARS concentration increases in response to chilling stress in fruit such as bananas [Musa acuminata (Promyou et al., 2008)] and mangoes [Mangifera indica (Ding et al., 2007)]. The higher LOX activity coupled with higher TBARS concentration indicated the cell membrane degradation resulting in EL and fruit softening during poststorage period. The higher levels of EL after 4 and 5 weeks of storage compared with the previous weeks indicated that membrane permeability increased substantially with the increase in CI incidence (Fig. 3C). Lipid peroxidation indicated by TBARS concentration and membrane degradation as marked by an increase of EL could possibly be the result of both $\mathrm{CI}$ and fruit senescence.

Antioxidant ENZYMe activities. SOD activity remained stable for the first 2 weeks of cold storage and showed a significant increase after 3 weeks of storage followed by a substantial decrease subsequently (Fig. 4A). The magnitude of decrease in SOD activity during simulated shelf conditions after 4 and 5 weeks of cold storage was significantly greater than that which occurred after the first 3 weeks of cold storage. CAT activity also showed a significant increase with the increase in storage period and reached a peak value after 3 weeks followed by a significant decline at 4 and 5 weeks of cold storage (Fig. 4B). CAT activity showed a decreasing trend during $8 \mathrm{~d}$ of simulated shelf conditions after each week of storage interval. POD activity increased significantly after 2 weeks of storage and exhibited a decrease during 3, 4, and 5 weeks (Fig. 4C). A continuous increase in POD activity was observed at shelf conditions after 0,1 , and 2 weeks of storage. However, POD activity showed a transient increase on day 4 during simulated shelf conditions after 3,4 , and 5 weeks of cold storage followed by a decline.

The exposure of fruit to prolonged chilling conditions can enhance the production of ROS, which must be quenched to maintain cellular redox homeostasis. It has been proposed that in response to low-temperature storage, the demand for adenosine triphosphate decreases in plants or plant parts,

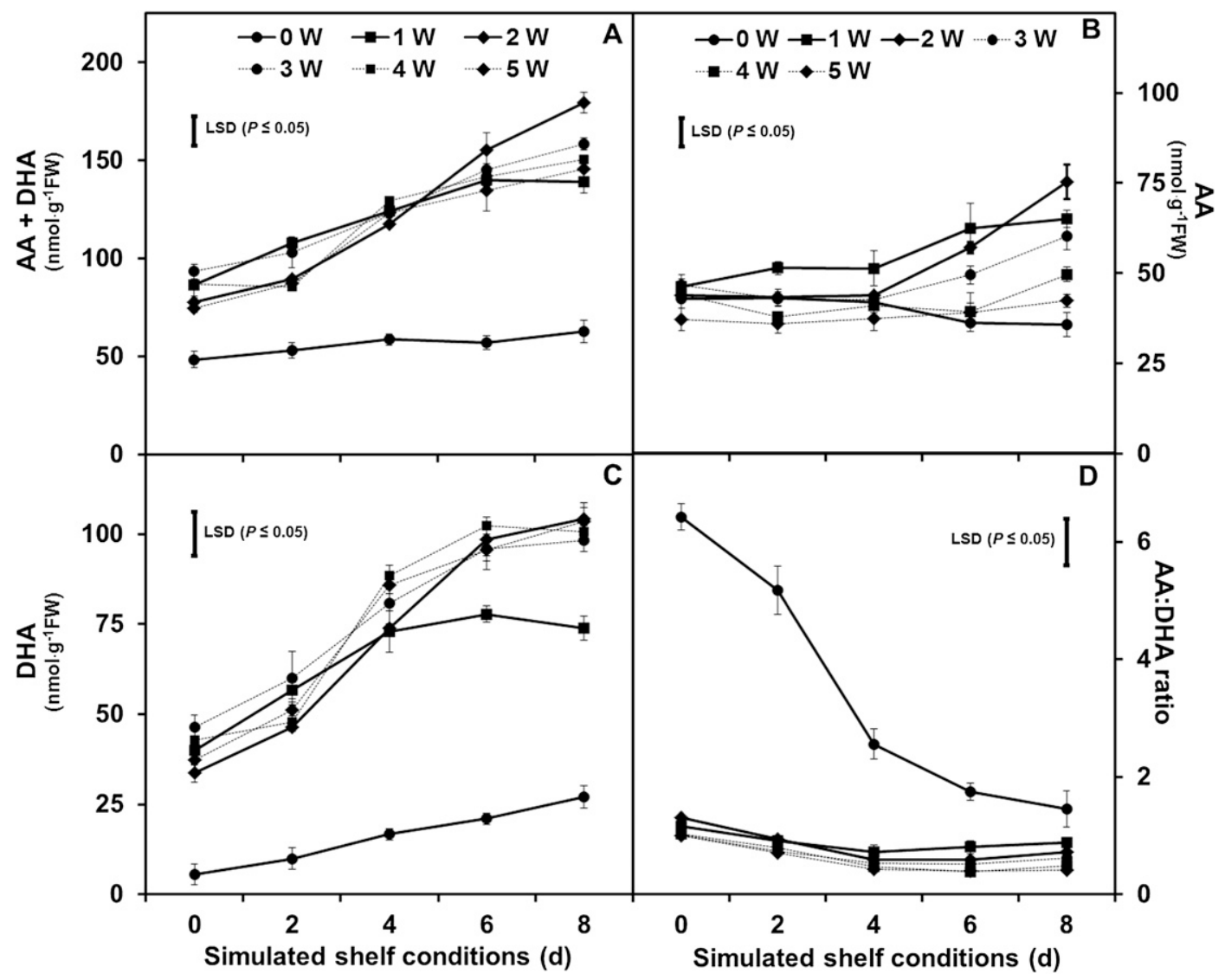

Fig. 5. Changes in concentrations of (A) total ascorbate [reduced ascorbate (AA) + oxidized ascorbate (DHA)], (B) AA, (C) DHA, and (D) AA:DHA ratio in the flesh tissue of 'Blackamber' japanese plums as influenced by cold storage at $0^{\circ} \mathrm{C}$ for 0 to 5 weeks (W) plus $8 \mathrm{~d}$ of simulated shelf conditions $\left(21 \pm 1{ }^{\circ} \mathrm{C}\right)$. Error bars represent SE. Least significant differences $(P \leq 0.05)$ for interaction between cold storage and simulated shelf conditions are shown as bars. 
resulting in an excess or overflow of electrons during electron transport chain in mitochondria and increased formation of ROS (Wismer, 2003). The antioxidant enzymes such as SOD, CAT, and POD are the primary lines of defense against the ROS to avoid their accumulation to toxic levels (Apel and Hirt, 2004). These enzymes act in a concerted manner to maintain ROS concentration at a low steady-state level. The decline in the activities of SOD and CAT at 4 and 5 weeks of cold storage (Fig. 4) suggested that the antioxidant protection system might have degraded and failed to cope with the increasing levels of stress resulting from prolonged chilling exposure. The activities of all these enzymes in the fruit flesh were significantly lower during simulated shelf conditions after 4 and 5 weeks of cold storage in comparison with the previous weeks of cold storage. The lower SOD activity can promote the abundance of $\mathrm{O}_{2} \cdot{ }^{\cdot-}$, which indirectly may increase the Haber-Weiss reaction rate leading to production of the most reactive and damaging hydroxyl radicals. The decreased activities of SOD, CAT, and POD were coincident with the higher incidence of CI after 5 weeks of storage (Figs. 2 and 4). The correlation analysis also showed that the severity of CI was negatively correlated with the activities of SOD $(r=-0.85)$, CAT $(r=-0.51)$, and POD $(r=-0.61)$. These observations imply that chilling damage occurred when activities of these antioxidant enzymes were relatively low. Previous studies have shown that higher activities of SOD and CAT in response to cold storage imparted chilling tolerance in mandarins [Citrus reticulata (Sala, 1998)] and mangoes (Zhao et al., 2009) and also conferred resistance against internal browning and skin scald in apples [Malus $\times$ domestica (Rao et al., 1998; Toivonen et al., 2003)].

Ascorbate-Glutathione CYCle. The increase in concentration of total ascorbate (AA + DHA) in fruit flesh during the first 3 weeks of storage may be attributed to an acclimation response to the chilling stress (Fig. 5A). The increase in total ascorbate was mainly the result of a increase in the concentration of DHA (Fig. 5C) because the AA levels showed nonsignificant changes during the same period (Fig. 5B). These observations showed that AA biosynthesis and oxidation were occurring simultaneously in 'Blackamber' japanese plums during cold storage and poststorage fruit ripening. The increase in AA was observed during simulated shelf conditions after the first 3 weeks of cold storage but not after 4 and 5 weeks. The lower AA:DHA ratio during simulated shelf conditions after 4 and 5 weeks of cold storage showed that the equilibrium shifted toward more oxidized state in the tissue in response to an extended storage period (Fig. 5D). The increase in AA during fruit ripening and chilling stress has also been reported in tomatoes [Solanum lycopersicum (Ioannidi et al., 2009; Stevens et al., 2008)]. The increased transcript level of L-galactose-1-phosphate phosphatase (GPP), a regulatory enzyme in the AA biosynthetic pathway, has been closely related to the increased AA production in response to ethylene, fruit ripening, and chilling stress in tomatoes (Ioannidi et al., 2009). Possibly, a similar mechanism of AA biosynthesis in ripening japanese plums may be operating under the control of GPP, when increased AA concentration is required in response to chilling stress.

Increased AA concentration in ripening fruit may also be the result of the combined action of oxidizing and recycling enzymes. The accumulation of DHA in fruit tissue could happen as a result of the increased activity of APX (Fig. 6A) and decreased activities of MDHAR (Fig. 6B) and DHAR

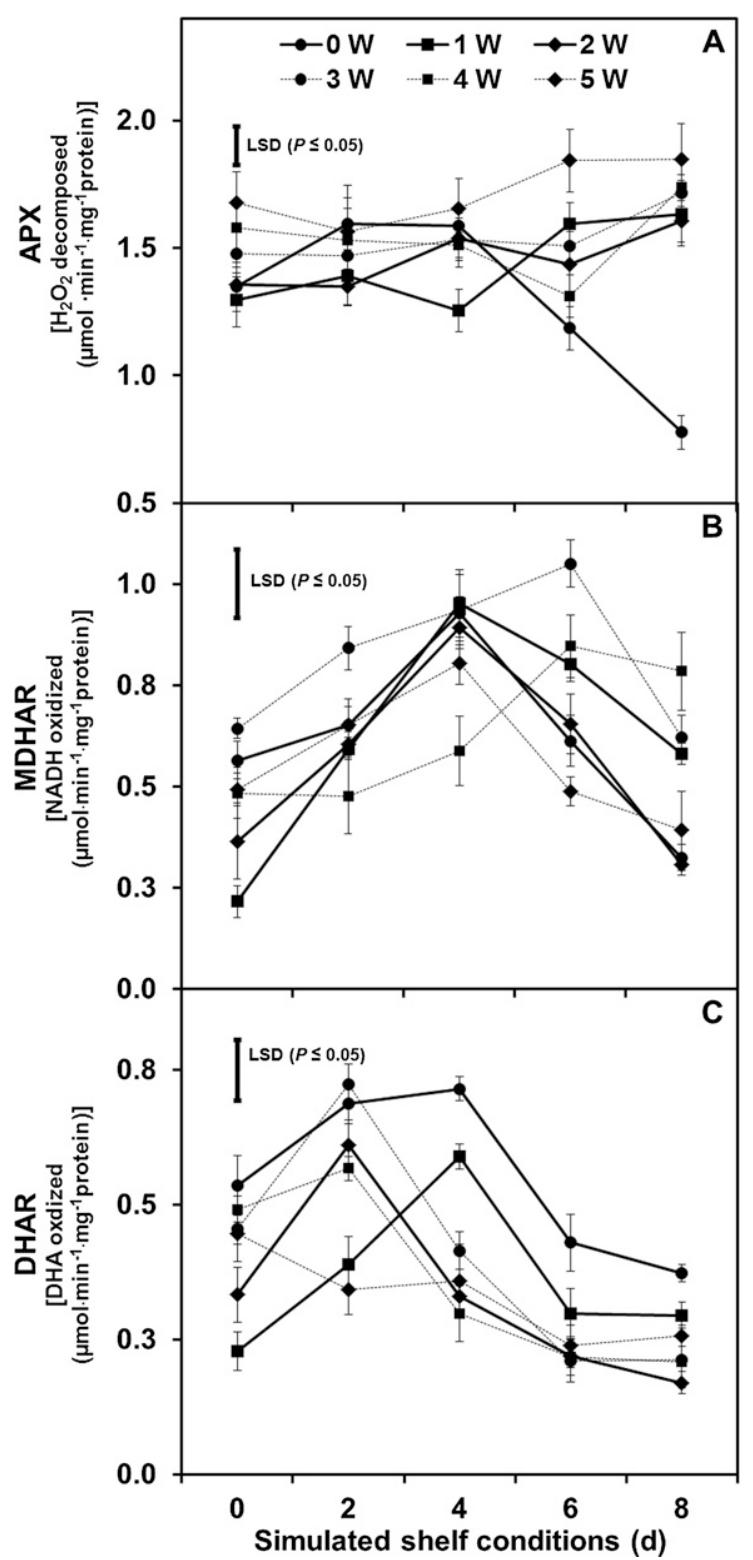

Fig. 6. Changes in activities of (A) ascorbate peroxidase (APX), (B) monodehydroascorbate reductase (MDHAR), and $(\mathbf{C})$ dehydroascorbate reductase (DHAR) in the flesh tissue of 'Blackamber' japanese plums as influenced by cold storage at $0{ }^{\circ} \mathrm{C}$ for 0 to 5 weeks (W) plus $8 \mathrm{~d}$ of simulated shelf conditions $\left(21 \pm 1{ }^{\circ} \mathrm{C}\right)$. Error bars represent SE. Least significant differences $(P \leq 0.05)$ for interaction between cold storage and simulated shelf conditions are shown as bars.

(Fig. 6C). The increase in APX activity during cold storage and simulated shelf conditions might have caused oxidation of AA into MDHA. MDHA is very unstable and thus spontaneously dismutates into DHA and AA. MDHAR activity also increased and reached a peak during initial stages of fruit ripening and then decreased (Fig. 6B). It is likely that decreased activity of MDHAR is one factor responsible for the accumulation of DHA toward day 8 of simulated shelf conditions. The increase in MDHAR enzyme activity and transcript levels has been linked to increase in the concentration of AA and chilling tolerance in tomatoes exposed to $4{ }^{\circ} \mathrm{C}$ for $40 \mathrm{~d}$ (Stevens et al., 2008). The data showed that the increased levels of DHA in fruit corresponded with the reduced activities of DHAR (Fig. 6C) and 


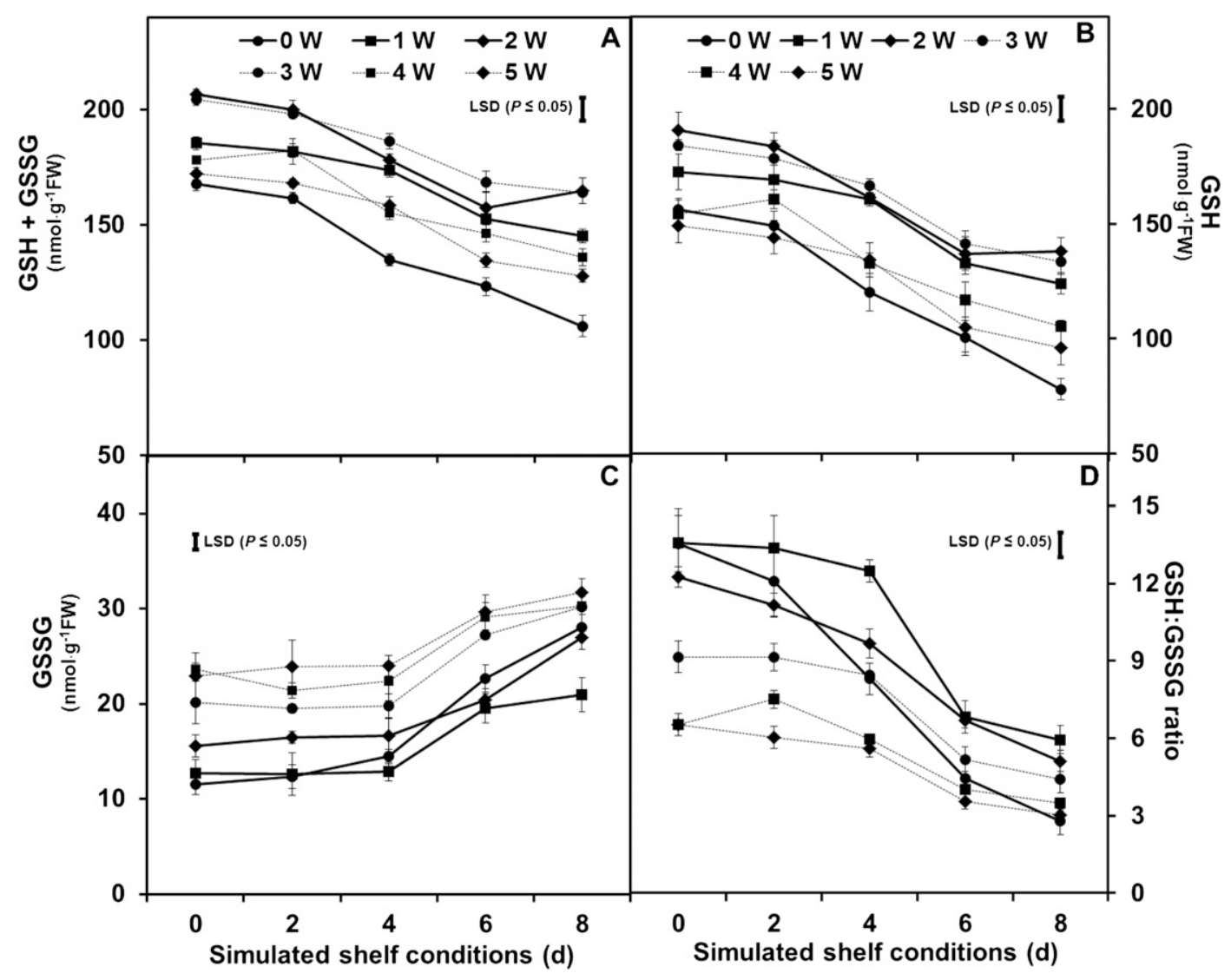

Fig. 7. Changes in concentrations of (A) total glutathione [reduced glutathione (GSH) + oxidized glutathione (GSSG)], (B) GSH, (C) GSSG, and (D) GSH:GSSG ratio in the flesh tissue of 'Blackamber' japanese plums as influenced by cold storage at $0{ }^{\circ} \mathrm{C}$ for 0 to 5 weeks (W) plus $8 \mathrm{~d}$ of simulated shelf conditions $\left(21 \pm 1{ }^{\circ} \mathrm{C}\right.$ ). Error bars represent SE. Least significant differences $(P \leq 0.05)$ for interaction between cold storage and simulated shelf conditions are shown as bars.

a negative correlation $(r=-0.64)$ existed between them. The increase in activities of MDHAR and DHAR indicated an acclamatory response to chilling stress, which helped the regeneration of AA toward restoration of the antioxidant potential of the fruit. However, the levels of AA and DHA could not be completely explained on the basis of activities of these oxidizing and recycling enzymes because of very weak correlations observed among these parameters. A study on the expression profiling of the AA biosynthesis, oxidation, and recycling genes in tomatoes has shown difficulties in explaining the levels of AA in response to various types of stresses resulting from biological complexities involved in various pathways (Ioannidi et al., 2009). Overall, no significant loss of AA was observed in 'Blackamber' japanese plums during 5 weeks of cold storage and a subsequent $8 \mathrm{~d}$ of simulated shelf conditions, which signified better storage potential of this cultivar. Previously, studies have also shown that the retention of AA during cold storage was linked to good storage characteristics in some cultivars of apple (Davey and Keulemans, 2004).

Concentrations of total glutathione (GSH + GSSG) and GSH increased during the first 2 weeks of storage followed by a continuous decline and reached the value equivalent to at harvest (Fig. 7A-B). In response to chilling, a transient increase in GSH levels has been reported in apples (Davey and Keulemans, 2004), suggesting the activation of the antioxidative system to combat the increasing production of ROS (Tausz et al., 2004). In general, a significant decrease in GSH levels has been reported to occur during long-term cold storage of other fruit such as mangoes (Zhao et al., 2009), oranges [Citrus sinensis (Huang et al., 2008)], and pawpaws [Asimina triloba (Galli et al., 2009)]. Apple cultivars high in GSH have been shown to exhibit better storage properties (Davey and Keulemans, 2004).

The regeneration of AA by the action of DHAR is driven by oxidation of GSH into GSSG (Apel and Hirt, 2004). The lower levels of DHAR activity were coincident with the increased levels of GSH during the first 2 weeks of storage compared with at harvest (Figs. 6C and 7B). Furthermore, the increased activities of DHAR for the first 2 to $4 \mathrm{~d}$ during simulated shelf conditions might have contributed to the decrease in GSH levels. In addition to DHAR, GR activity also determines the concentration of GSH in the pool as it catalyzes the reduction of GSSG into GSH. The increase in GR in response to the first 2 to 3 weeks of cold storage might have helped to regenerate the GSH (Fig. 8A). As the storage duration progressed, the capacity of GR to recycle GSH diminished and a similar trend was observed during simulated shelf conditions after each week of cold storage. The GR activity and GSH concentration were found to be positively correlated $(r=0.84)$ with each other. The decline in the activity of GR (Fig. 8A) also corresponded with the increase in concentration of GSSG (Fig. 7C) with a negative correlation $(r=-0.66)$. Chilling stress has been implicated in decreased GR activity in orange (Huang et al., 2008) and peach [Prunus persica (Wang et al., 2006)]. GT is also involved in providing protection against oxidative stress by detoxifying lipid hydroperoxides through the use of GSH as a reductant. It is 


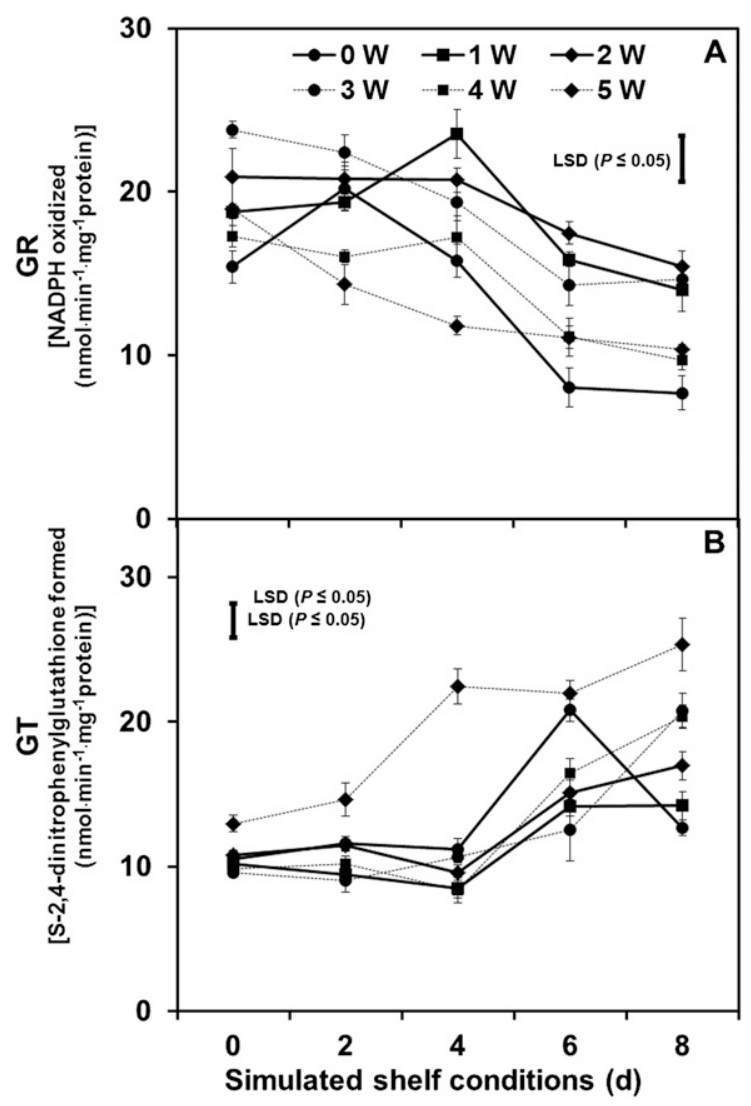

Fig. 8. Changes in activities of (A) glutathione reductase (GR) and (B) glutathione-S-transferase (GT) in the flesh tissue of 'Blackamber' japanese plums as influenced by cold storage at $0{ }^{\circ} \mathrm{C}$ for 0 to 5 weeks (W) plus $8 \mathrm{~d}$ of simulated shelf conditions $\left(21 \pm 1{ }^{\circ} \mathrm{C}\right)$. Error bars represent SE. Leas significant differences $(P \leq 0.05)$ for interaction between cold storage and simulated shelf conditions are shown as bars.

therefore likely that a decrease in GSH and increase in GSSG is also related to the increased activity of GT required to counteract increasing lipid peroxidation products during advanced stages of storage (Fig. 8B). The accumulation of GSSG and decrease in GSH would have led to a decrease in the GSH:GSSG ratio in japanese plum and european plum fruit flesh tissue as reported in pawpaw (Galli et al., 2009).

TotAl PHENOLICS AND ANTIOXIDANT ACTIVITY. The increase in concentration of total phenolics during initial storage period could be the result of activation of phenylpropanoid metabolism in response to chilling stress as reported in grapes [Vitis vinifera (Sanchez-Ballesta et al., 2007)], pawpaws (Galli et al., 2009), and japanese plums (Díaz-Mula et al., 2009) (Fig. 9A). The increased production of phenolic compounds in the tissue imparts resistance against different abiotic and biotic stresses (Sanchez-Ballesta et al., 2007). On the other hand, the prolonged storage for 4 and 5 weeks resulted in decrease in concentration of total phenolics (Fig. 9A), which could possibly be the result of their use as a substrate of polyphenol oxidase in the browning reactions involved in CI (Galli et al., 2009) and also as antioxidants in peroxidase-mediated removal of $\mathrm{H}_{2} \mathrm{O}_{2}$ because of the coexistence of phenolics and peroxidases in the vacuoles. The data showed that severity of CI was negatively correlated $(r=-0.70)$ with the concentration of total phenolics. The prolonged storage has been shown to cause a decrease in the

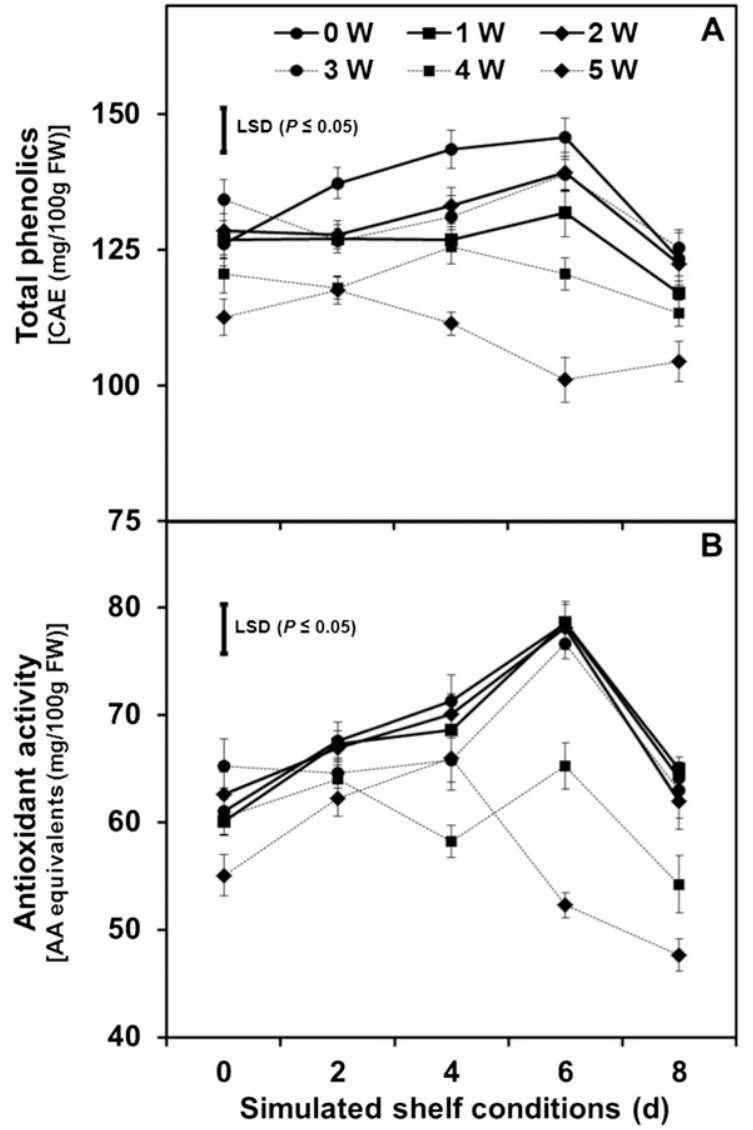

Fig. 9. Changes in total phenolics concentration expressed as chlorogenic acid equivalents (CAE) (A) and antioxidant activity expressed as ascorbic acid (AA) equivalents (B) in the flesh tissue of 'Blackamber' japanese plums as influenced by cold storage at $0{ }^{\circ} \mathrm{C}$ for 0 to 5 weeks (W) plus $8 \mathrm{~d}$ of simulated shelf conditions $\left(21 \pm 1{ }^{\circ} \mathrm{C}\right)$. Error bars represent SE. Least significant differences $(P \leq 0.05)$ for interaction between cold storage and simulated shelf conditions are shown as bars.

levels of phenolics in grapes (Sanchez-Ballesta et al., 2007), mangoes (Zhao et al., 2009), and pawpaws (Galli et al., 2009).

The antioxidant capacity in the flesh tissue of japanese plums is mainly the result of the presence of phenolic compounds; very little contribution by other compounds has been reported (Díaz-Mula et al., 2009; Gil et al., 2002). The pattern of changes in antioxidant activity was similar to the changes in total phenolics (Fig. 9B) and a positive correlation $(r=0.76)$ was observed between them. It could be argued that phenolic compounds in cooperation with other antioxidative components during initial stages of storage contributed to maintaining ROS at low levels and thus protected the tissue from oxidative injury. The increase in storage duration accompanied by the decrease in total phenolics and reduced efficiency of other antioxidative systems might have contributed to the build-up of oxidative stress to potentially damaging levels.

Our data illustrated the dynamics of enzymatic and nonenzymatic antioxidative systems in 'Blackamber' japanese plums during up to 5 weeks of cold storage at $0{ }^{\circ} \mathrm{C}$ followed by 0 to $8 \mathrm{~d}$ of simulated shelf conditions after each week of storage. The third week of storage at $0{ }^{\circ} \mathrm{C}$ was identified as the critical point after which degeneration of the antioxidative system proceeded and led to near collapse during shelf conditions after 5 weeks of cold storage. If the response of antioxidant systems is taken into 
account, it would be considered safe to cold-store these fruit for 3 weeks. The possibility of increasing storage duration beyond 3 weeks adds to the risk of expression of CI. The storage duration of 3 weeks does not seem to be sufficient to accommodate fruit marketing and long-distance marine transport. In light of this, postharvest strategies have to be adopted to reduce the lipid peroxidation and strengthen the antioxidative systems to reduce the risk of development of CI in japanese plums.

\section{Literature Cited}

Apel, K. and H. Hirt. 2004. Reactive oxygen species: Metabolism, oxidative stress and signal transduction. Annu. Rev. Plant Biol. 55:373-399.

Brand-Williams, W., M.E. Cuvelier, and C. Berset. 1995. Use of a free radical method to evaluate antioxidant activity. LWT-Food Sci. Technol. 28:25-30.

Candan, A.P., J. Graell, and C. Larrigaudière. 2008. Roles of climacteric ethylene in the development of chilling injury in plums. Postharvest Biol. Technol. 47:107-112.

Chun, O.K. and D.O. Kim. 2004. Consideration on equivalent chemicals in total phenolic assay of chlorogenic acid-rich plums. Food Res. Intl. 37:337-342.

Crisosto, C.H., D. Garner, G.M. Crisosto, and E. Bowerman. 2004. Increasing 'Blackamber' plum (Prunus salicina Lindell) consumer acceptance. Postharvest Biol. Technol. 34:237-244.

Crisosto, C.H., F.G. Mitchell, and Z. Ju. 1999. Susceptibility to chilling injury of peach, nectarine, and plum cultivars grown in California. HortScience 34:1116-1118.

Davey, M.W., C. Franck, and J. Keulemans. 2004. Distribution, developmental and stress responses of antioxidant metabolism in Malus. Plant Cell Environ. 27:1309-1320.

Davey, M.W. and J. Keulemans. 2004. Determining the potential to breed for enhanced antioxidant status in Malus: Mean inter- and intravarietal fruit vitamin $\mathrm{C}$ and glutathione contents at harvest and their evolution during storage. J. Agr. Food Chem. 52:8031-8038.

Díaz-Mula, H.M., P.J. Zapata, F. Guillén, D. Martínez-Romero, S. Castillo, M. Serrano, and D. Valero. 2009. Changes in hydrophilic and lipophilic antioxidant activity and related bioactive compounds during postharvest storage of yellow and purple plum cultivars. Postharvest Biol. Technol. 51:354-363.

Ding, Z., S.P. Tian, X. Zheng, Z. Zhou, and Y. Xu. 2007. Responses of reactive oxygen metabolism and quality in mango fruit to exogenous oxalic acid or salicylic acid under chilling temperature stress. Physiol. Plant. 130:112-121.

Galli, F., D.D. Archbold, and K.W. Pomper. 2009. Pawpaw fruit chilling injury and antioxidant protection. J. Amer. Soc. Hort. Sci. 134:466-471.

Gil, M.I., F.A. Tomás-Barberán, B. Hess-Pierce, and A.A. Kader. 2002. Antioxidant capacities, phenolic compounds, carotenoids, and vitamin $\mathrm{C}$ contents of nectarine, peach, and plum cultivars from California. J. Agr. Food Chem. 50:4976-4982.

Hodges, D.M. and C.F. Forney. 2000. The effects of ethylene, depressed oxygen, and elevated carbon dioxide on antioxidant profiles of senescing spinach leaves. J. Expt. Bot. 51:645-655.

Hodges, D.M., G.E. Lester, K.D. Munro, and P.M.A. Toivonen. 2004. Oxidative stress: Importance for postharvest quality. HortScience 39:924-929.

Huang, R., J. Liu, Y. Lu, and R. Xia. 2008. Effect of salicylic acid on the antioxidant system in the pulp of 'Cara Cara' navel orange (Citrus sinensis L. Osbeck) at different storage temperatures. Postharvest Biol. Technol. 47:168-175.

Ioannidi, E., M.S. Kalamaki, C. Engineer, I. Pateraki, D. Alexandrou, I. Mellidou, J. Giovannonni, and A.K. Kanellis. 2009. Expression profiling of ascorbic acid-related genes during tomato fruit development and ripening and in response to stress conditions. J. Expt. Bot. 60:663-678.

Khan, A.S. and Z. Singh. 2009. 1-MCP application suppresses ethylene biosynthesis and retards fruit softening during cold storage of 'Tegan Blue' japanese plum. Plant Sci. 176:539-544.

Promyou, S., S. Ketsa, and W.G. van Doorn. 2008. Hot water treatments delay cold-induced banana peel blackening. Postharvest Biol. Technol. 48:132-138.

Rao, M.V., C.B. Watkins, S.K. Brown, and N.F. Weeden. 1998. Active oxygen species metabolism in 'White Angel' $\times$ 'Rome Beauty' apple selections resistant and susceptible to superficial scald. J. Amer. Soc. Hort. Sci. 123:299-304.

Sala, J.M. 1998. Involvement of oxidative stress in chilling injury in cold-stored mandarin fruits. Postharvest Biol. Technol. 13:255-261.

Sanchez-Ballesta, M.T., I. Romero, J.B. Jiménez, J.M. Orea, A. González-Ureña, M.I. Escribano, and C. Merodio. 2007. Involvement of the phenylpropanoid pathway in the response of table grapes to low temperature and high $\mathrm{CO}_{2}$ levels. Postharvest Biol. Technol. 46:29-35.

Shewfelt, R.L. and A.C. Purvis. 1995. Towards a comprehensive model for lipid peroxidation in plant tissue disorders. HortScience 30:213-218.

Singh, S.P. and Z. Singh. 2012. Postharvest oxidative behaviour of 1-methylcyclopropene treated japanese plums (Prunus salicina Lindell) during storage under controlled and modified atmospheres. Postharvest Biol. Technol. 74:26-35.

Singh, S.P., Z. Singh, and E.E. Swinny. 2009. Postharvest nitric oxide fumigation delays fruit ripening and alleviates chilling injury during cold storage of japanese plums (Prunus salicina Lindell). Postharvest Biol. Technol. 53:101-108.

Singh, S.P., Z. Singh, and E.E. Swinny. 2012. Climacteric level during fruit ripening influences lipid peroxidation and enzymatic and nonenzymatic antioxidative systems in japanese plums (Prunus salicina Lindell). Postharvest Biol. Technol. 65:22-32.

Singleton, V.L., R. Orthofer, and R.M. Lamuela-Raventos. 1999. Analysis of total phenols and other oxidation substrates and antioxidants by means of Folin-Ciocalteu reagent. Methods Enzymol. 299:152-178.

Stevens, R., D. Page, B. Gouble, C. Garchery, D. Zamir, and M. Causse. 2008. Tomato fruit ascorbic acid content is linked with monodehydroascorbate reductase activity and tolerance to chilling stress. Plant Cell Environ. 31:1086-1096.

Tausz, M., H. Šircelj, and D. Grill. 2004. The glutathione system as a stress marker in plant ecophysiology: Is a stress-response concept valid? J. Expt. Bot. 55:1955-1962.

Toivonen, P.M.A. 2004. Postharvest storage procedures and oxidative stress. HortScience 39:938-942.

Toivonen, P.M.A., P.A. Wiersma, Y. Gong, and O.L. Lau. 2003. Levels of antioxidant enzymes and lipid soluble antioxidants are associated with susceptibility to internal browning in 'Braeburn' apples. Acta Hort. 600:57-61.

Tomás-Barberán, F.A., M.I. Gil, P. Cremin, B. Hess-Pierce, A.L. Waterhouse, and A.A. Kader. 2001. HPLC-DAD-ESIMS analysis of phenolic compounds in nectarines, peaches, and plums. J. Agr. Food Chem. 49:4748-4760.

Wang, L., S. Chen, W. Kong, S. Li, and D.D. Archbold. 2006. Salicylic acid pre-treatment alleviates chilling injury and affects the antioxidant system and heat shock proteins of peaches during cold storage. Postharvest Biol. Technol. 41:244-251.

Wismer, W.V. 2003. Low temperature as a causative agent of oxidative stress in postharvest crops, p. 55-68. In: Hodges, D.M. (ed.). Postharvest oxidative stress in horticultural crops. Food Products Press, New York, NY.

Zhao, Z., J. Cao, W. Jiang, Y. Gu, and Y. Zhao. 2009. Maturity-related chilling tolerance in mango fruit and the antioxidant capacity involved. J. Sci. Food Agr. 89:304-309. 